Catalysts for Nitrogen Fixation 
Nitrogen Fixation: Origins, Applications, and Research Progress VOLUME 1 


\section{Catalysts for Nitrogen Fixation}

\section{Nitrogenases, Relevant Chemical Models and Commercial Processes}

Edited by

Barry E. Smith

Emeritus Fellow,

John Innes Centre, Colney, Norwich, U.K.

Raymond L. Richards

Chemistry Department,

University of Sussex, Brighton, U.K.

and

William E. Newton

Department of Biochemistry,

Virginia Polytechnic Institute \& State University, Blacksburg, U.S.A.

Springer-Science+Business Media, B.V. 
A C.I.P. Catalogue record for this book is available from the Library of Congress.

ISBN 978-90-481-6675-6 ISBN 978-1-4020-3611-8 (eBook)

DOI 10.1007/978-1-4020-3611-8

background figure caption:

"A seed crop of clover (Trifolium hirtum) in flower near Moora, Western Australia. Photograph courtesy of Mike Davies, Senior Technical Officer, Pasture Research Group of Agriculture WA and reproduced with permission."

\section{Caption for "Volume I Specific Cover Figure"}

A comparison of the solution structure of the Azotobacter vinelandii MoFe protein as determined by x-ray scattering with the published crystallographic structure, showing that the solid-state structure is conserved in solution. This figure was published as Figure $2 b$ of Comparing Crystallographic and Solution Structures of Nitrogenase Complexes by Grossman, J. G., Hasnain, S. S., Yousafzai, F. K., Smith, B. E., Eady, R. R., Schindelin, H., Kisker, C., Howard, J. B., Tsuruta, H., Müller, J., and Rees, D. C. (1999) Acta Cryst. D55, 727728 and is reproduced by permission of the International Union of Crystallography.

\section{Printed on acid-free paper}

\section{All Rights Reserved}

\section{(C) 2004 Springer Science+Business Media Dordrecht}

Originally published by Kluwer Academic Publishers in 2004

Softcover reprint of the hardcover 1st edition 2004

No part of this work may be reproduced, stored in a retrieval system, or transmitted in any form or by any means, electronic, mechanical, photocopying, microfilming, recording or otherwise, without written permission from the Publisher, with the exception of any material supplied specifically for the purpose of being entered and executed on a computer system, for exclusive use by the purchaser of the work. 


\section{TABLE OF CONTENTS}

Preface to the Series. . . . . . . . . . . . . . . . . . . . . .

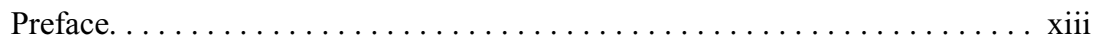

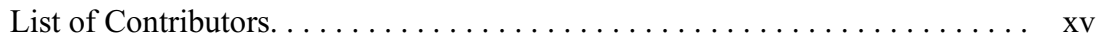

Chapter 1. Nitrogen Fixation: An Historical Perspective

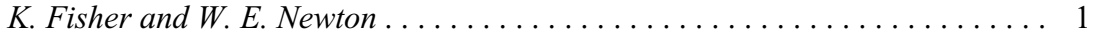

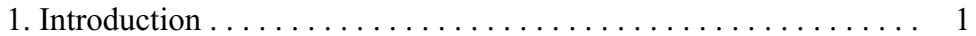

2. When Did Biological Nitrogen Fixation Appear? . . . . . . . . . 3

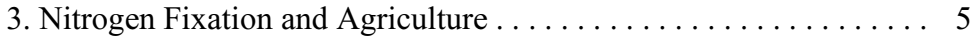

4. Do Plants Assimilate Nitrogen from the Air? . . . . . . . . . . 7

5. Are Bacteria Responsible for Assimilating Nitrogen from the Air? . 9

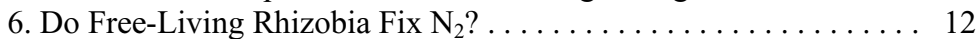

7. Commercial Application of Biological Nitrogen Fixation . . . . . 13

8. Commercial Application of Industrial Nitrogen Fixation . . . . . . 14

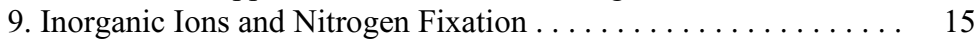

10. Methods Used for the Detection of Nitrogen Fixation . . . . . . 16

11. Beginning of the Biochemistry of Biological Nitrogen Fixation . . 18

12. Cell-free Extracts and Beyond .................. 24

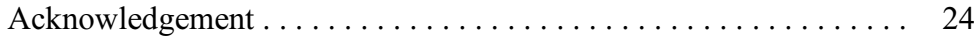

References ........................... 26

Chapter 2. Haber-Bosch and Other Industrial Processes

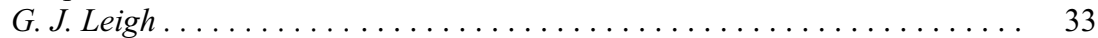

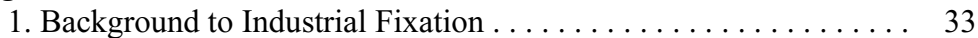

2. Dinitrogen Chemistry up to $c a .1900 \ldots \ldots \ldots \ldots \ldots \ldots \ldots \ldots . \ldots \ldots$

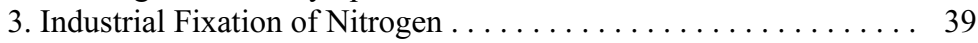

4. Developments since $c a .1920 \ldots \ldots \ldots \ldots \ldots \ldots \ldots \ldots \ldots . \ldots 48$

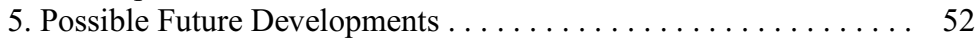

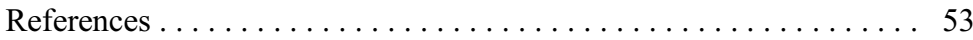

Chapter 3. Assay Methods for Products of Nitrogenase Action on Substrates

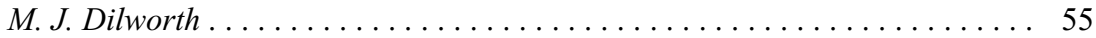

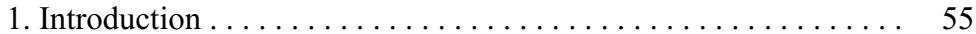

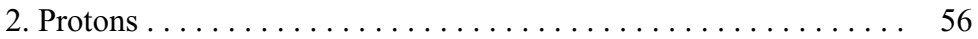

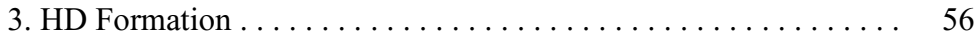

4. Nitrogenous Substrates . . . . . . . . . . . . . . . 57

5. Carbon-containing Substrates . . . . . . . . . . . . . 63

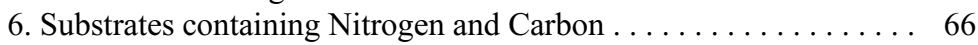

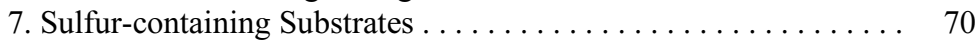

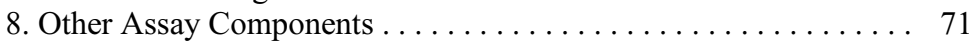

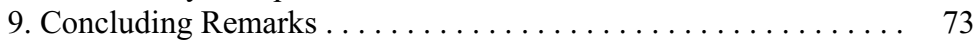

References ........................... 73 
Chapter 4. The Structures of the Nitrogenase Proteins and Stabilized Complexes

P. M. C. Benton and J. W. Peters . . . . . . . . . . . . . . . . . . . . . . 77

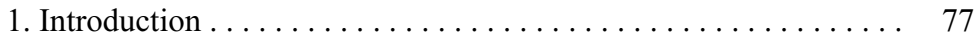

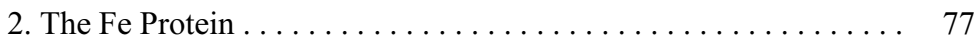

3. The MoFe Protein ..................... 81

4. Nitrogenase Complex Structures . . . . . . . . . . . . . . . 87

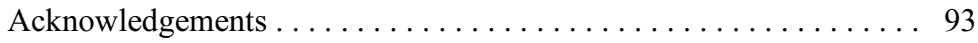

References ............................. 93

Chapter 5. The Mechanism of Mo-dependent Nitrogenase: Thermodynamics and

Kinetics R. Y. Igarashi and L. C. Seefeldt . . . . . . . . . . . . . . . . . 97

1. Introduction . . . . . . . . . . . . . . . . . . . . . . 97

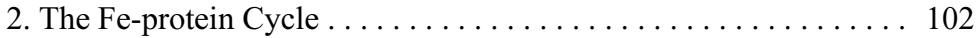

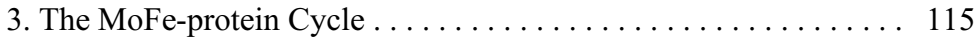

4. Future Prospects . . . . . . . . . . . . . . . . . . . 132

References .............................. 133

Chapter 6. Strategies for the Functional Analysis of the Azotobacter vinelandii $\mathrm{MoFe}$ Protein and its Active Site FeMo-cofactor

S. M. Mayer, P. C. Dos Santos, L. C. Seefeldt and D. R. Dean ... . . . . . 141

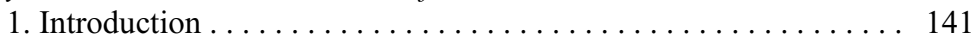

2. Genetic Manipulation and Biochemical Techniques for the

Study of $A$. vinelandii Nitrogenase . . . . . . . . . . . 142

3. Insights gained into Nitrogenase Structure-Function from

Genetic and Biochemical Studies . . . . . . . . . . . . . 148

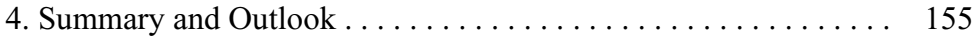

References ........................... 157

Chapter 7. Chemical Models, Throretical Calculations, and Reactivity of Isolated Iron-Molybdenum Cofactor

F. Barrière, M. C. Durrant and C. J. Pickett . . . . . . . . . . . . . 161

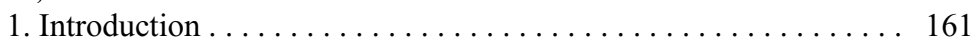

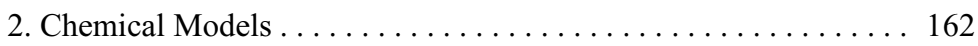

3. Theoretical Calculations ................... 171

4. Isolation and Reactivity of the Nitrogenase FeMo-cofactor. . . . . . 181

5. Summary and Future Prospects . . . . . . . . . . . . . . 190

References ............................ 192

Chapter 8. Structural Models for the FeMo-cofactor and the P Clusters

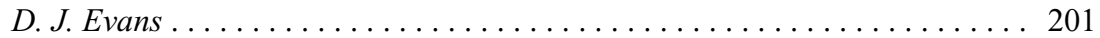

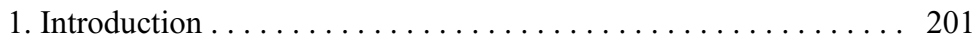

2. FeMo-cofactor Models . . . . . . . . . . . . . . . . . . . . . . 203

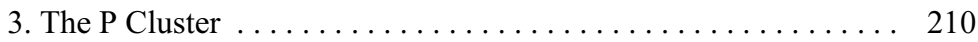

4. Concluding Remarks .......................... 214

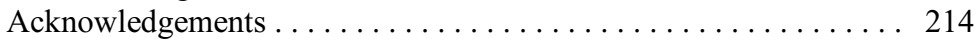

References ............................... 215 
Chapter 9. Biosynthesis of Iron-Molybdenum and Iron-Vanadium Cofactors of the nif- and vnf-encoded Nitrogenases

P. W. Ludden, P. Rangaraj and L. M. Rubio. . . . . . . . . . . . . . . . . . . . . 219

1. Introduction . . . . . . . . . . . . . . . . . . . . . . 219

2. Discovery and Characterization of FeMo-cofactor ......... 219

3. Structures of FeMo-cofactor and FeV-cofactor and their Sites in the MoFe and $\mathrm{VFe}$ Proteins ................ 221

4. FeMo-cofactor and FeV-cofactor Biosynthesis. . . . . . . . 223

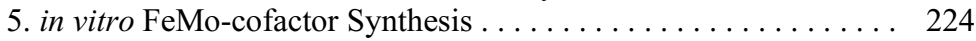

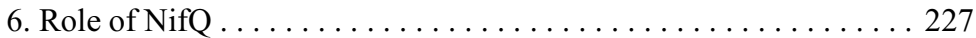

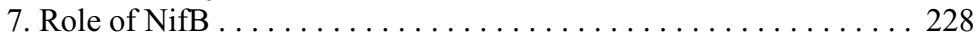

8. Role of NifNE . . . . . . . . . . . . . . . . . . . . . 229

9. Role NifH. . . . . . . . . . . . . . . . . . 231

10. NifV and the Role of Homocitrate . . . . . . . . . . 235

11. Role of NifX . . . . . . . . . . . . . . . . . . . . 238

12. Role of NifU . . . . . . . . . . . . . . . . . . . . . 239

13. Role of NifS . . . . . . . . . . . . . . . . . . . . 240

14. Role of NifM ......................... 240

15. Roles of NifW and NifZ ..................... 241

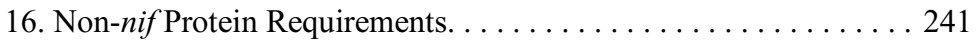

17. Role of VnfG . . . . . . . . . . . . . . . . . . . . 242

18. Role of Nucleotides and Divalent Metals in FeMo-cofactor

Synthesis ....................... 243

19. Model for the Biosynthesis of FeMo-cofactor and FeV-cofactor . 243

References............................. 247

Chapter 10. Vanadium Nitrogenase

B. J. Hales . . . . . . . . . . . . . . . . . . . . . . . . . . . . . . . . . . . . 255

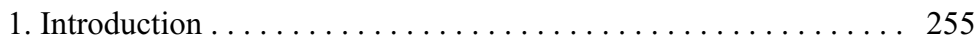

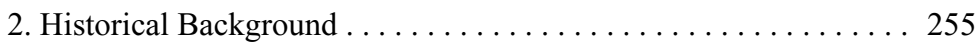

3. Characterization ........................... 258

4. Mechanism ............................... 267

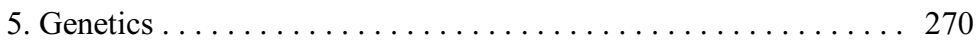

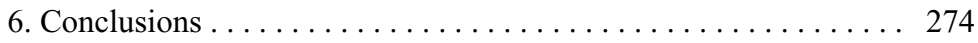

References ............................ 275

Chapter 11. Iron-only Nitrogenase: Exceptional Catalytic, Structural and Spectroscopic Features

K. Schneider and A. Müller . . . . . . . . . . . . . . . . . . . . . . . . 281

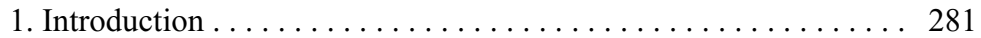

2. Metal Regulation of Nitrogenases . . . . . . . . . . . . 283

3. Factors Influencing Biosynthesis, Catalytic Activity, and

Stability of Fe-nitrogenases . . . . . . . . . . . . . . . . 284

4. Mo- and Fe-nitrogenases: Comparison of Subunit Composition,

Amino-acid Sequences and Immuno-reactions . . . . . . . . 287

5. Structures of the Iron-Sulfur Clusters in Fe-nitrogenase . . . . . . . 290 
viii

6. EPR and Redox Properties of the Rhodobacter FeFe Protein . . . . 295

7. Catalytic Characteristics of Iron-only Nitrogenases . . . . . . . . . . 299

8. Fe-only Nitrogenase: Evolutionary Relic or Important

Complementary Enzyme System for Diazotrophic Bacteria? 302

9. Summary and Outlook . . . . . . . . . . . . . . . . . . . 304

Acknowledgements . . . . . . . . . . . . . . . . . . . . . 304

References .............................. 304

Chapter 12. Superoxide-dependent Nitrogenase

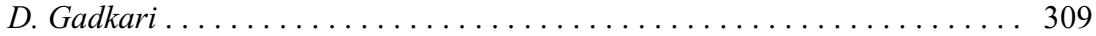

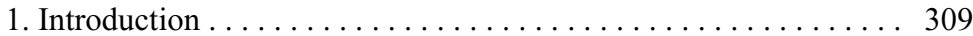

2. Description of Streptomyces thermoautotrophicus . . . . . . . 310

3. Components of the Superoxide-dependent

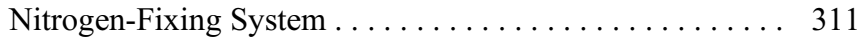

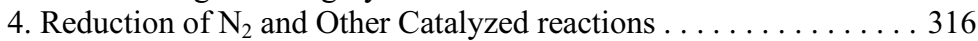

5. Genetics . . . . . . . . . . . . . . . . . . . . . . . 324

6. Conclusions and Perspectives ................... 328

References .......................... 330

Chapter 13. Future Challenges and Prospects

R. L. Richards and B. E. Smith . . . . . . . . . . . . . . . . . . . . . 333

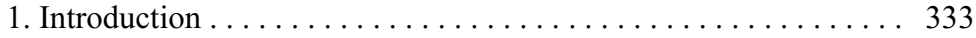

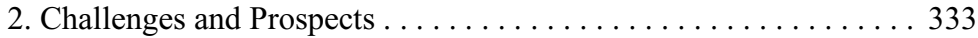

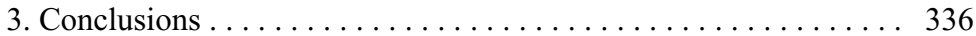

References ........................... 336

Subject Index. . . . . . . . . . . . . . . . . . . . . . . . 337 


\section{SERIES PREFACE}

\section{Nitrogen Fixation: Origins, Applications, and Research Progress}

Nitrogen fixation, along with photosynthesis as the energy supplier, is the basis of all life on Earth (and maybe elsewhere too!). Nitrogen fixation provides the basic component, fixed nitrogen as ammonia, of two major groups of macromolecules, namely nucleic acids and proteins. Fixed nitrogen is required for the N-containing heterocycles (or bases) that constitute the essential coding entities of deoxyribonucleic acids (DNA) and ribonucleic acids (RNA), which are responsible for the high-fidelity storage and transfer of genetic information, respectively. It is also required for the amino-acid residues of the proteins, which are encoded by the DNA and that actually do the work in living cells. At the turn of the millennium, it seemed to me that now was as good a time as any (and maybe better than most) to look back, particularly over the last 100 years or so, and ponder just what had been achieved. What is the state of our knowledge of nitrogen fixation, both biological and abiological? How has this knowledge been used and what are its impacts on humanity?

In an attempt to answer these questions and to capture the essence of our current knowledge, I devised a seven-volume series, which was designed to cover all aspects of nitrogen-fixation research. I then approached my long-time contact at Kluwer Academic Publishers, Ad Plaizier, with the idea. I had worked with Ad for many years on the publication of the Proceedings of most of the International Congresses on Nitrogen Fixation. My personal belief is that congresses, symposia, and workshops must not be closed shops and that those of us unable to attend should have access to the material presented. My solution is to capture the material in print in the form of proceedings. So it was quite natural for me to turn to the printed word for this detailed review of nitrogen fixation. Ad's immediate affirmation of the project encouraged me to share my initial design with many of my current co-editors and, with their assistance, to develop the detailed contents of each of the seven volumes and to enlist prospective authors for each chapter.

There are many ways in which the subject matter could be divided. Our decision was to break it down as follows: nitrogenases, commercial processes, and relevant chemical models; genetics and regulation; genomes and genomics; associative, endophytic, and cyanobacterial systems; actinorhizal associations; leguminous symbioses; and agriculture, forestry, ecology, and the environment. I feel very fortunate to have been able to recruit some outstanding researchers as coeditors for this project. My co-editors were Mike Dilworth, Claudine Elmerich, John Gallon, Euan James, Werner Klipp, Bernd Masepohl, Rafael Palacios, Katharina Pawlowski, Ray Richards, Barry Smith, Janet Sprent, and Dietrich Werner. They worked very hard and ably and were most willing to keep the volumes moving along reasonably close to our initial timetable. All have been a pleasure to work with and I thank them all for their support and unflagging interest. 
Nitrogen-fixation research and its application to agriculture have been ongoing for many centuries - from even before it was recognized as nitrogen fixation. The Romans developed the crop-rotation system over 2000 years ago for maintaining and improving soil fertility with nitrogen-fixing legumes as an integral component. Even though crop rotation and the use of legumes was practiced widely but intermittently since then, it wasn't until 1800 years later that insight came as to how legumes produced their beneficial effect. Now, we know that bacteria are harbored within nodules on the legumes' roots and that they are responsible for fixing $\mathrm{N}_{2}$ and providing these plants with much of the fixed nitrogen required for healthy growth. Because some of the fixed nitrogen remains in the unharvested parts of the crop, its release to the soil by mineralization of the residue explains the follow-up beneficial impact of legumes. With this realization, and over the next 100 years or so, commercial inoculants, which ensured successful bacterial nodulation of legume crops, became available. Then, in the early 1900's, abiological sources of fixed nitrogen were developed, most notable of these was the Haber-Bosch process. Because fixed nitrogen is almost always the limiting nutrient in agriculture, the resulting massive increase in synthetic fixed-nitrogen available for fertilizer has enabled the enormous increase in food production over the second half of the $20^{\text {th }}$ century, particularly when coupled with the new "green revolution" crop varieties. Never before in human history has the global population enjoyed such a substantial supply of food.

Unfortunately, this bright shiny coin has a slightly tarnished side! The abundance of nitrogen fertilizer has removed the necessity to plant forage legumes and to return animal manures to fields to replenish their fertility. The result is a continuing loss of soil organic matter, which decreases the soil's tilth, its waterholding capacity, and its ability to support microbial populations. Nowadays, farms do not operate as self-contained recycling units for crop nutrients; fertilizers are trucked in and meat and food crops are trucked out. And if it's not recycled, how do we dispose of all of the animal waste, which is rich in fixed nitrogen, coming from feedlots, broiler houses, and pig farms? And what is the environmental impact of its disposal? This problem is compounded by inappropriate agricultural practice in many countries, where the plentiful supply of cheap commercial nitrogen fertilizer, plus farm subsidies, has encouraged high (and increasing) application rates. In these circumstances, only about half (at best) of the applied nitrogen reaches the crop plant for which it was intended; the rest leaches and "runs off" into streams, rivers, lakes, and finally into coastal waters. The resulting eutrophication can be detrimental to marine life. If it encroaches on drinking-water supplies, a human health hazard is possible. Furthermore, oxidation of urea and ammonium fertilizers to nitrate progressively acidifies the soil - a major problem in many agricultural areas of the world. A related problem is the emission of nitrogen oxides $\left(\mathrm{NO}_{\mathrm{x}}\right)$ from the soil by the action of microorganisms on the applied fertilizer and, if fertilizer is surface broadcast, a large proportion may be volatilized and lost as ammonia. For urea in rice paddies, an extreme example, as much as $50 \%$ is volatilized and lost to the atmosphere. And what goes up must come down; in the case of fertilizer nitrogen, it returns to Earth in the rain, often acidic in nature. This 
uncontrolled deposition has unpredictable environmental effects, especially in pristine environments like forests, and may also affect biodiversity.

Some of these problems may be overcome by more efficient use of the applied fertilizer nitrogen. A tried and tested approach (that should be used more often) is to ensure that a balanced supply of nutrients (and not simply applying more and more) is applied at the right time (maybe in several separate applications) and in the correct place (under the soil surface and not broadcast). An entirely different approach that could slow the loss of fertilizer nitrogen is through the use of nitrification inhibitors, which would slow the rate of conversion of the applied ammonia into nitrate, and so decrease its loss through leaching. A third approach to ameliorating the problems outlined above is through the expanded use of biological nitrogen fixation. It's not likely that we shall soon have plants, which are capable of fixing $\mathrm{N}_{2}$ without associated microbes, available for agricultural use. But the discovery of $\mathrm{N}_{2}$-fixing endophytes within the tissues of our major crops, like rice, maize, and sugarcane, and their obvious benefit to the crop, shows that real progress is being made. Moreover, with new techniques and experimental approaches, such as those provided by the advent of genomics, we have reasons to renew our belief that both bacteria and plants may be engineered to improve biological nitrogen fixation, possibly through developing new symbiotic systems involving the major cereal and tuber crops.

In the meantime, the major impact might be through agricultural sustainability involving the wider use of legumes, reintroduction of crop-rotation cycles, and incorporation of crop residues into the soil. But even these practices will have to be performed judiciously because, if legumes are used only as cover crops and are not used for grazing, their growth could impact the amount of cultivatable land available for food crops. Even so, the dietary preferences of developed countries (who eats beans when steak is available?) and current agricultural practices make it unlikely that the fixed-nitrogen input by rhizobia in agricultural soils will change much in the near-term future. A significant positive input could accrue, however, from matching rhizobial strains more judiciously with their host legumes and from introducing "new" legume species, particularly into currently marginal land. In the longer term, it may be possible to engineer crops in general, but cereals in particular, to use the applied fertilizer more efficiently. That would be a giant step the right direction. We shall have to wait and see what the ingenuity of mankind can do when "the chips are down" as they will be sometime in the future as food security becomes a priority for many nations. At the moment, there is no doubt that commercially synthesized fertilizer nitrogen will continue to provide the key component for the protein required by the next generation or two.

So, even as we continue the discussion about the benefits, drawbacks, and likely outcomes of each of these approaches, including our hopes and fears for the future, the time has arrived to close this effort to delineate what we know about nitrogen fixation and what we have achieved with that knowledge. It now remains for me to thank personally all the authors for their interest and commitment to this project. Their efforts, massaged gently by the editorial team, have produced an indispensable reference work. The content is my responsibility and I apologize 
upfront for any omissions and oversights. Even so, I remain confident that these volumes will serve well the many scientists researching nitrogen fixation and related fields, students considering the nitrogen-fixation challenge, and administrators wanting to either become acquainted with or remain current in this field. I also acknowledge the many scientists who were not direct contributors to this series of books, but whose contributions to the field are documented in their pages. It would be remiss of me not to acknowledge also the patience and assistance of the several members of the Kluwer staff who have assisted me along the way. Since my initial dealings with Ad Plaizier, I have had the pleasure of working with Arno Flier, Jacco Flipsen, Frans van Dunne, and Claire van Heukelom; all of whom provided encouragement and good advice - and there were times when I needed both!

It took more years than I care to remember from the first planning discussions with Ad Plaizier to the completion of the first volumes in this series. Although the editorial team shared some fun times and a sense of achievement as volumes were completed, we also had our darker moments. Two members of our editorial team died during this period. Both Werner Klipp (1953-2002) and John Gallon (19442003) had been working on Volume II of the series, Genetics and Regulation of Nitrogen-Fixing Bacteria, and that volume is dedicated to their memory. Other major contributors to the field were also lost in this time period: Barbara Burgess, whose influence reached beyond the nitrogenase arena into the field of iron-sulfur cluster biochemistry; Johanna Döbereiner, who was the discoverer and acknowledged leader in nitrogen-fixing associations with grasses; Lu Jiaxi, whose "string bag" model of the FeMo-cofactor prosthetic group of Mo-nitrogenase might well describe its mode of action; Nikolai L'vov, who was involved with the early studies of molybdenum-containing cofactors; Dick Miller, whose work produced new insights into MgATP binding to nitrogenase; Richard Pau, who influenced our understanding of alternative nitrogenases and how molybdenum is taken up and transported; and Dieter Sellmann, who was a synthetic inorganic chemistry with a deep interest in how $\mathrm{N}_{2}$ is activated on metal sites. I hope these volumes will in some way help both preserve their scientific contributions and reflect their enthusiasm for science. I remember them all fondly.

Only the reactions and interest of you, the reader, will determine if we have been successful in capturing the essence and excitement of the many sterling achievements and exciting discoveries in the research and application efforts of our predecessors and current colleagues over the past 150 years or so. I sincerely hope you enjoy reading these volumes as much as I've enjoyed producing them.

William E. Newton

Blacksburg, February 2004 


\section{PREFACE}

\section{Catalysts for Nitrogen Fixation: Nitrogenases, Relevant Chemical Models and Commercial Processes}

This is Volume I of a seven-volume series on all aspects of Nitrogen Fixation, covering both the biological and the industrial processes. The aim of the series is to produce a definitive, authoritative survey of the whole subject which should act as a benchmark for some years to come. A major positive feature is that each volume has sufficient space to deal with its subject matter in depth, thus making it an important reference base. To ensure the quality of the reportage, we have assembled a group of internationally respected experts as our authors.

In establishing the contents of Volume I of the series, we realised that we needed to start with an historical perspective, from the initial recognition that biological nitrogen fixation existed through to the first successful preparations of the active cell-free extracts on which most subsequent enzymatic studies have been based. Then, because modern agriculture could not exist without major inputs from the nitrogenous fertilizer produced industrially, Chapter 2 describes the development of an industrial method for fixing atmospheric $\mathrm{N}_{2}$, largely from an historical viewpoint, but leading to a description of the modern Haber-Bosch process.

Chapter 3 then begins our coverage of the nitrogenases. All nitrogenases catalyze the reduction of a number of small, generally triple-bonded, substrates, in addition to $\mathrm{N}_{2}$, sometimes to one and sometimes to several products. When trying to understand the chemistry carried out by the enzymes, suitable assays for these products are essential and Chapter 3 describes the assay systems currently used to quantify the products.

To date, four enzyme systems capable of fixing atmospheric $\mathrm{N}_{2}$ have been isolated from bacteria. Of these, the most common and by far the best studied is molybdenum nitrogenase, which consists of two $\mathrm{O}_{2}$-sensitive metalloproteins, the $\mathrm{MoFe}$ and $\mathrm{Fe}$ proteins (sometimes called either components 1 and 2 or dinitrogenase and dinitrogenase reductase). Because of the importance and ubiquity of this enzyme, we have devoted three chapters exclusively to it. Chapter 4 describes the $\mathrm{x}$-ray crystallographic structures of the two proteins and the complex formed between them and provides the protein data bank accession numbers for each structure described to allow interested readers to examine the structures in more detail at their leisure. Chapter 5 then describes what is known about the mechanism of the enzyme and Chapter 6 details current studies to establish the site of substrate binding, i.e., just where on the prosthetic group called the FeMo-cofactor (often referred to as FeMoco) do substrates bind and become reduced. Chapter 6 also includes a description of the methodology for preparing the site-directed mutants of Azotobacter vinelandii that have been used in attempts to address the question of substrate binding among others.

Chapters 7 and 8 describe non-enzymatic studies directed toward trying to understand the biological process. Chapter 7 first outlines inorganic complex 
chemistry, which attempts to model the functional chemistry of the enzyme. A number of possible reaction mechanisms for the biological process have been developed from such studies. Next, the recent computational approaches to the problem of the binding and activation of $\mathrm{N}_{2}$ on the FeMo-cofactor, when bound within the enzyme, are subjected to critical analysis. This study is followed by a description of the chemical and electrochemical reactivity of the FeMo-cofactor, after its extraction from the MoFe protein. This extremely $\mathrm{O}_{2}$-sensitive species has not yet been induced to reduce $\mathrm{N}_{2}$ to ammonia, but both the evolution of $\mathrm{H}_{2}$ from protons and the reduction of acetylene to ethylene have been demonstrated.

Chapter 8 describes chemists' attempts to emulate the structures of both the FeMo-cofactor and the second type of prosthetic group found in the MoFe protein, which is called the $\mathrm{P}$ cluster. There has been an enormous amount of work in this area but, unfortunately, much of the work pre-dated the accurate definition of the structure of these clusters by means of high-resolution x-ray crystallography. Therefore, only the most relevant work is described here. Following this discussion of attempted chemical synthesis of structures akin to the FeMo-cofactor, Chapter 9 outlines what is known about the biosynthesis of the FeMo-cofactor and its counterparts, the FeV-cofactor and the FeFe-cofactor, from two of the other nitrogenases, the vanadium and iron-only enzymes. As yet, these studies have not provided many clues for the synthetic chemists, although the order of the steps in the biosyntheses is becoming clearer.

Having described the molybdenum nitrogenase in great detail, it is then appropriate to present Chapters 10,11 and 12, which respectively describe the state of current knowledge on the vanadium, the iron-only, and the superoxide-dependent nitrogenases and also include many comparisons with the more intensively studied molybdenum enzyme. As is made clear in Chapter 12, the superoxide-dependent enzyme appears to resemble the pterin-containing molybdenum hydroxylases and oxidoreductases rather than the other three nitrogenases. Finally, Chapter 13 gives our own summary of the current challenges and likely prospective advances in the fields covered by this volume.

It has taken about two years from its inception to complete this volume and we would like to thank all of the authors who committed so much effort and submitted so readily to our editorial requirements in order to ensure that the final product is of such high quality. However, we must end on a note of sadness because, during these two years, we have lost three colleagues, the biochemists Barbara Burgess and Richard Pau and the inorganic chemist Dieter Sellmann, all of whom contributed a great deal to the field covered by this volume. They will be sorely missed.

Barry E. Smith

Norwich, February, 2004

Raymond L. Richards

Brighton, February, 2004

William E. Newton

Blacksburg, February, 2004 


\section{LIST OF CONTRIBUTORS}

Frédéric BARRIÈRE,

Université de Rennes I, Institut de

Chimie, UMR CNRS 6510,

35042 Rennes, France.

Email: frederic.barriere@univrennes1.fr

\section{Paul M.C. BENTON}

Department of Chemistry and

Biochemistry, Montana State

University, Bozeman, MT 59717,

U.S.A.

Email: benton@chemistry.

montanta.edu

\section{Dennis R. DEAN}

Department of Biochemistry, Virginia Polytechnic Institute and State University, Blacksburg, VA 24061, U.S.A.

Email: deandr@vt.edu

\section{Michael J. DILWORTH}

Center for Rhizobium Studies, School of Biological Sciences and Biotechnology, Murdoch University, Murdoch, Western Australia.

Email: dilworth@murdoch.edu.au

\section{Patricia C. DOS SANTOS}

Department of Biochemistry, Virginia Polytechnic Institute and State University, Blacksburg, VA 24061, U.S.A.

Email: pdossantr@vt.edu

\section{Marcus C. DURRANT}

Department of Biological Chemistry, John Innes Centre, Norwich

Research Park, Colney Lane, Norwich NR4 7UH, U.K.

Email: marcus.durrant@bbsrc.ac.uk
David J. EVANS

Department of Biological Chemistry, John Innes Centre, Norwich Research Park, Colney Lane, Norwich NR4 7UH, U.K.

Email: dave.evans@bbsrc.ac.uk

Karl FISHER

Department of Biochemistry, Virginia Polytechnic Institute and State University, Blacksburg, VA 24061, U.S.A.

Email: fisherk@vt.edu

\section{Dilip GADKARI}

Chair of Microbiology, University of Bayreuth, D-95440 Bayreuth, Germany.

Email: Dilip.Gadkari@unibayreuth.de

\section{Brian J. HALES}

Department of Chemistry, Louisiana State University, Baton Rouge, LA 70803-1804, U.S.A.

Email: brian.hales@chem.lsu.edu

\section{Robert Y. IGARASHI}

Department of Chemistry and Biochemistry, Utah State University, Logan, UT 84322-0300, U.S.A.

Email: rigarashi@cc.usu.edu

G. Jeffery LEIGH

Chemistry Department, School of Life Sciences, University of Sussex, Brighton BN1 9QJ, U.K. Email: G.J.Leigh@sussex.ac.uk 


\section{Paul W. LUDDEN}

Department of Plant and Microbial

Biology, University of California,

Berkeley, CA 94720, U.S.A.

Email: pludden@nature.berkeley.edu

Suzanne M. MAYER

Department of Biochemistry, Virginia Polytechnic Institute and

State University, Blacksburg,

VA 24061, U.S.A.

Email: sumayer@vt.edu

Achim MÜLLER

Universität Bielefeld, Fakultät für

Chemie, Lehrstuhl für Anorganische

Chemie I, D-33615 Bielefeld,

Germany.

Email: a.mueller@uni-bielefeld.de

William E. NEWTON

Department of Biochemistry, Virginia Polytechnic Institute and

State University, Blacksburg, VA 24061, U.S.A.

Email: wenewton@vt.edu

John W. PETERS

Department of Chemistry and

Biochemistry, Montana State

University, Bozeman, MT 59717,

U.S.A.

Email: john.peters@chemistry. montanta.edu

Christopher J. PICKETT

Department of Biological Chemistry, John Innes Centre, Norwich

Research Park, Colney Lane, Norwich NR4 7UH, U.K.

Email: chris.pickett@bbsrc.ac.uk
Priya RANGARAJ

Pierce Biotechnology,

3747 N Meridian Rd, Rockford,

IL 61105, U.S.A.

Email: priya.rangaraj@piercenet.com

Raymond L. RICHARDS

Chemistry Department, School of

Life Sciences, University of Sussex,

Brighton BN1 9QJ, U.K.

Email: R.Richards@sussex.ac.uk

Luis M. RUBIO

Department of Plant and Microbial

Biology, University of California,

Berkeley, CA 94720, U.S.A.

Email: lrubio@nature.berkeley.edu

Klaus SCHNEIDER

Universität Bielefeld, Fakultät für

Chemie, Lehrstuhl für Anorganische

Chemie I, D-33615 Bielefeld,

Germany.

Email: klaus.schneider1@uni-

bielefeld.de

Lance C. SEEFELDT

Department of Chemistry and

Biochemistry, Utah State University,

Logan, UT 84322-0300, U.S.A.

Email: seefeldt@cc.usu.edu

Barry E. SMITH

Department of Biological Chemistry,

John Innes Centre, Norwich

Research Park, Colney Lane,

Norwich NR4 7UH, U.K.

Email: barry.smith@bbsrc.ac.uk 